\title{
Article
}

\section{The Influence of Hard- and Software Improvement of Intraoral Scanners on the Implant Transfer Accuracy from 2012 to 2021: An In Vitro Study}

\author{
Alexander Schmidt ${ }^{1, *}$, Maximiliane Amelie Schlenz ${ }^{1}{ }^{1}$, Haoyu Liu ${ }^{1}$, Holger Sebastian Kämpe ${ }^{2}$ \\ and Bernd Wöstmann ${ }^{1}$ \\ 1 Dental Clinic-Department of Prosthodontics, Justus Liebig University, Schlangenzahl 14, \\ 35392 Giessen, Germany; maximiliane.a.schlenz@dentist.med.uni-giessen.de (M.A.S.); \\ haoyu.liu@dentist.med.uni-giessen.de (H.L.); bernd.woestmann@dentist.med.uni-giessen.de (B.W.) \\ 2 Dental Practice, Rommelstr. 1, 35708 Haiger, Germany; holger.kaempe@gmail.com \\ * Correspondence: alexander.schmidt@dentist.med.uni-giessen.de; Tel.: +49-641-9946150
}

check for updates

Citation: Schmidt, A.; Schlenz, M.A.; Liu, H.; Kämpe, H.S.; Wöstmann, B. The Influence of Hard- and Software Improvement of Intraoral Scanners on the Implant Transfer Accuracy from 2012 to 2021: An In Vitro Study. Appl. Sci. 2021, 11, 7166. https:// doi.org/10.3390/app11157166

Academic Editors: Paola Gandini and Andrea Scribante

Received: 25 June 2021

Accepted: 1 August 2021

Published: 3 August 2021

Publisher's Note: MDPI stays neutral with regard to jurisdictional claims in published maps and institutional affiliations.

Copyright: (c) 2021 by the authors. Licensee MDPI, Basel, Switzerland. This article is an open access article distributed under the terms and conditions of the Creative Commons Attribution (CC BY) license (https:// creativecommons.org/licenses/by/ $4.0 /)$.

\begin{abstract}
This study aimed to investigate the transfer accuracy (trueness and precision) of three different intraoral scanning families using different hardware and software versions over the last decade from 2012 to 2021, compared to a conventional impression. Therefore, an implant master model with a reference cube was digitized and served as a reference dataset. Digital impressions of all three scanning families (True definition, TRIOS, CEREC) were recorded ( $n=10$ per group), and conventional implant impressions were taken $(n=10)$. The conventional models were digitized, and all models (conventional and digital) were measured. Therefore, it was possible to obtain the deviations between the master model and the scans or conventional models in terms of absolute three-dimensional (3D) deviations, deviations in rotation, and angulation. The results for deviations between the older and newer scanning systems were analyzed using pairwise comparisons $(p<0.05$; SPSS 26). The absolute 3D deviations increased with increasing scan path length, particularly for the older hardware and software versions (old vs. new (MW \pm SD) True Definition: $355 \pm 62 \mu \mathrm{m}$ vs. $483 \pm 110 \mu \mathrm{m}$; TRIOS: $574 \pm 274 \mu \mathrm{m}$ vs. $258 \pm 100 \mu \mathrm{m}$; and CEREC: $1356 \pm 1023 \mu \mathrm{m}$ vs $110 \pm 49 \mu \mathrm{m})$. This was also true for deviations in rotation and angulation. The conventional impression showed an advantage only regarding the absolute 3D deviation compared to the older systems. Based on the data of the present study, the accuracy of intraoral scanners is decisively related to hardware and software; though, newer systems or software do not necessarily warrant improvement. Nevertheless, to achieve high transfer accuracy, regular updating of digital systems is recommended. The challenge of increasing errors with increasing scan paths is overcome in the most recent systems. The combination of two different scanning principles in a single device seems to be beneficial.
\end{abstract}

Keywords: dental implants; digital dentistry; dental impression technique; dimensional measurement accuracy; intraoral scanner

\section{Introduction}

Intraoral scanners (IOSs) have demonstrated ceaseless development since their introduction in 1985; therefore, currently, a wide range of digital scanners are available for a dental practice, and the use of IOSs is part of the daily practice routine for a continuously increasing number of dentists [1,2]. Numerous studies on IOS are available, most dealing with different aspects of accuracy, some addressing handling, and a few focusing on the further development and implementation of digital processes [3-7]. However, all these aspects are necessarily related to the capabilities of the actual scanners used in this study [8]. Although improvements have occurred over the years, the underlying reasons for the differences are difficult to distinguish as they may be related to the study setup, 
the operator's experience, or the scanners themselves. To the best of our knowledge, no study has compared different generations of scanner families in an identical study setup over the years. For each of the three different scanning principles (optical triangulation technique, active wavefront sampling, and confocal laser scanning systems), a typical scanner is included. As only a single scanner family uses active wavefront sampling, this family is also included, although the respective manufacturer will discontinue the scanner and the future of the system is unclear.

A large number of studies have shown that various factors influence the accuracy of intraoral scans. To date, a lack of calibration [9], the scanning path [10,11], and the users themselves [12] were identified as potentially influential factors. While IOS could already reach or even exceed the accuracy of conventional impressions for single teeth [13], the situation, for a long time, with regard to impressions of natural teeth, especially across the quadrant, was that IOS could not reach the level of accuracy of conventional impressions $[14,15]$. However, in more recent studies, it was demonstrated that IOS impressions within a quadrant and even beyond could achieve even better results than with conventional impression methods $[3,16]$. With regard to implant impressions, the results of a previous clinical study even showed similar results between conventional and digital impression methods when taking impressions of maxillary situations or partially edentulous jaw sections [4]. Comparable results were also obtained in other studies [17,18].

Although IOS are constantly being developed and improved, only a few studies [19-21] are available where different software versions were examined and described as potentially influencing the transfer accuracy of IOS. However, within one study, only two different software versions of a scanner family were investigated with regard to the accuracy of single tooth preparations. It was found that the software version can have an influence on the result of the transfer accuracy [19]. In a further study, the influence of different parameters during the production of crowns was investigated. Two different software versions of a scanner were also used [20]. The most recent study on the influence of different software versions was investigated in relation to the accuracy of different restorative materials [21]. However, none of these studies investigated the influence on the transfer accuracy of implants. Furthermore, the transfer accuracy of implants by intraoral scanners is of specific interest, since implants have a tenfold lower mobility compared to natural teeth which requires an enormously high transfer accuracy from the oral situation to the model situation [22,23]. For this reason, an implant model setup with a corresponding reference key offers excellent possibilities for standardization over the years, due to the fact that the implant model structures are precisely prefabricated and remain dimensionally stable over a long period of time. Thus, implant models represent identical basic situations. Therefore, in order to eliminate possible external influences such as different study setups, the influence of scanbodies, or measuring strategies $[4,16,24-26]$ in the present study, two investigators assessed the transfer accuracy (trueness and precision) of three different IOS families using different hardware and software versions from 2012 to 2021 and compared them to a conventional impression (CI) on the same implant model over a period of ten years. According to ISO 5725-1, mean values for the deviations between the IOS results and the master model describing trueness and standard deviation describing precision for the different scanners and the CI [27].

The null hypothesis tested was as follows. There are no differences in the transfer accuracy for different IOSs with different hardware and software versions.

\section{Materials and Methods}

To simulate a clinically close setup, a partially edentulous maxillary model was used as an implant master model (IMM). The model shows a typical patient situation with one interrupted and one unilaterally shortened arch.

The base plate $(100 \times 100 \mathrm{~mm})$ of the model is made of stainless steel, into which four steel tubes for implant placement (positions 16, 14, 25, and 26 of the Federation Dentaire Internationale [FDI]) were inserted. 
Four steel tubes for implant placement (positions 16, 14, 25, and 26 of the Federation Dentaire Internationale [FDI]) were inserted in the stainless steel base plate $(10 \times 10 \mathrm{~cm})$ of the IMM, and Straumann RN Standard Plus implants (Straumann, Freiburg, Germany) were adhesively luted in the tubes (14 mm length, $4.8 \mathrm{~mm}$ diameter; Galvano AGC-Cem adhesive, Wieland-Dental, Würzburg, Germany). Two references cubes (RC, perpendicular to each other) were inserted in FDI positions 18 and 23. The basic structure of a partially edentulous upper was modelled of pink-colored methyl methacrylate (PalaXpress, Kulzer, Hanau, Germany; Figure 1).

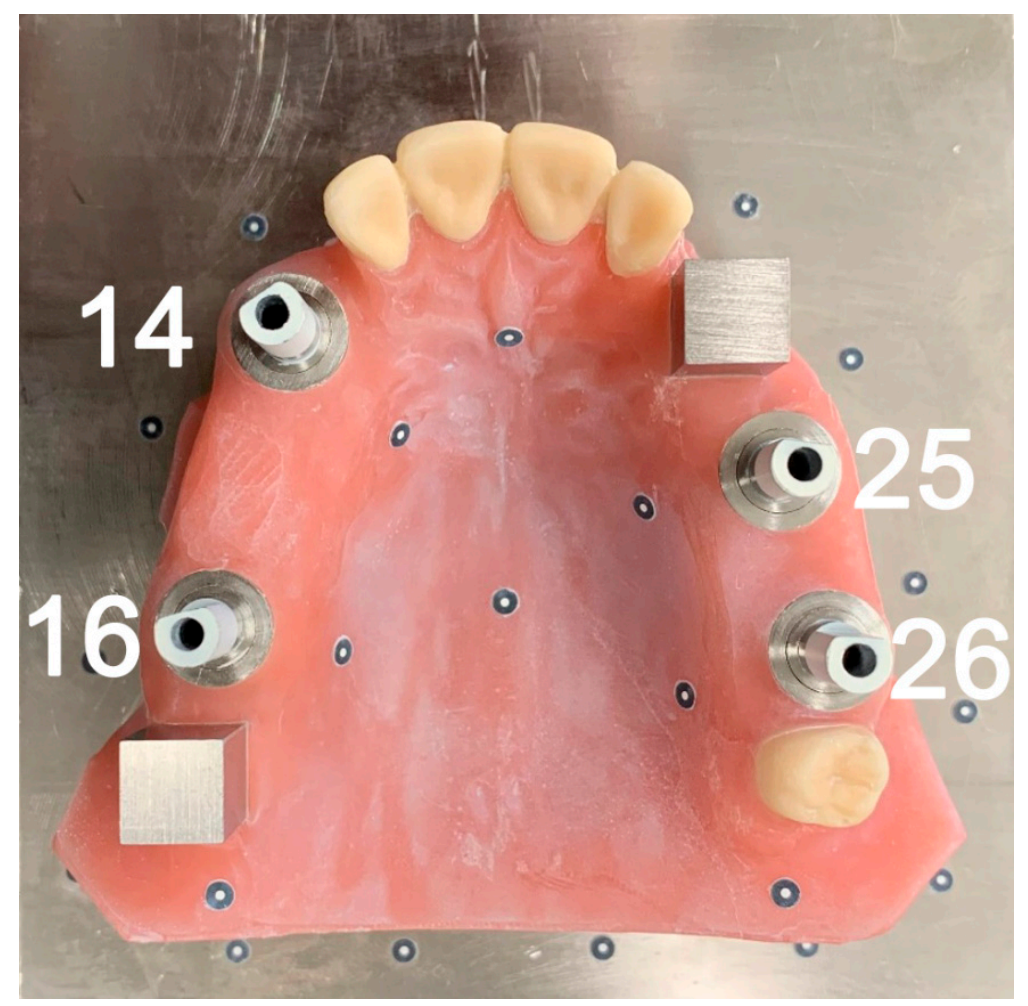

Figure 1. Implant master model (IMM) with two reference cubes and final setup with inserted scan bodies (FDI 16, 14, 25, 26).

To determine the implant positions, the IMM was digitized using a coordinate measuring machine (CMM, Thome Rapid, Thome precision, Messel, Germany, accuracy $2.2 \mu \mathrm{m})$ with the corresponding software Metrolog (Metrologic Group, Meylan, France). Therefore, the upper surface of the individual scanbodies were touched and defined as a plane. Then, the lateral surfaces of the scanbodies were touched and defined as cylinders. The known length of the scanbodies made it possible to transfer the plane of the surface to the implant-abutment interface point by means of a parallel shift. To determine the length of the scanbodies precisely, they were also measured with the CMM (Thome Rapid, Thome precision, Messel, Germany) during preliminary tests. The defined plane on the scanbodies as well as the definiton of the cylinder also made it possible to determine the angulation of the scanbodies. The same applies to the rotation, which could be defined on the basis of another flat surface on the outer surface of the cylinder of the scanbody.

Based on the reference cube (RC; FDI 18) on the IMM, a coordinate system was defined as reference. Scan data were exported as a standard tessellation language (STL) file format, serving as a reference file.

Four intraoral scanbodies (ISBs; N1410, Medentika, Hügelsheim, Germany) were screwed in the implants $(15 \mathrm{Ncm})$ of the IMM for the digital impressions. The H1410 ISB consists of a cylindrical titanium base and a flattened plane in the upper part.

Scans were performed using three different IOS families: True Definition Scanner (3M, St. Paul, MN, USA), which is based on active wavefront sampling; the TRIOS 
family (3Shape, Copenhagen, Denmark) based on confocal laser scanning microscopy; and the Sirona CEREC Omnicam/Primescan family (Sirona, Bensheim, Germany) with an optical triangulation technique. Primescan additionally uses confocal microscopy [28,29] as a second acquisition principle. The scanners used in the corresponding software versions are listed in Table 1.

Table 1. Intraoral scanning systems with corresponding software versions used in the present study.

\begin{tabular}{|c|c|c|c|c|}
\hline Scanner Family & Type & Software Version & Release Date & Label \\
\hline \multirow{3}{*}{$\begin{array}{l}\text { True Definition } \\
\text { Scanner }\end{array}$} & True Definition scanner (Cart version) & 4.0 .3 & 2013-04 & TD_4.1 \\
\hline & True Definition scanner (Cart version) & 5.4 & 2018-07 & TD_5.4 \\
\hline & True Definition scanner (Portable version) & 5.4 & 2018-07 & TDpb_5.4 \\
\hline \multirow{2}{*}{ TRIOS } & TRIOS II & 2013-01 & 2013-01 & TR2 \\
\hline & TRIOS 4 & 19.2.4 & 2020-12 & TR4 \\
\hline \multirow{3}{*}{ CEREC } & CEREC Omnicam & 4.2.1.61068 & 2012-04 & OC_4 4.2 \\
\hline & CEREC Omnicam & 4.6.1.152739 & 2018-05 & OC_4.6 \\
\hline & CEREC Primescan & 5.1.0.190461 & 2020-05 & PS \\
\hline
\end{tabular}

Two trained and calibrated examiners (H. L. and H. S. K.) performed 10 full-arch scans using the calibrated scanners and followed the scanning paths, recommended by the different manufacturers, which were as follows: scan started at the occluso-palatal surfaces of the right molar in the maxillary (including the RCs), moved towards the second quadrant constantly including the palatal surfaces, then again to the RCs, and to the occlusal surfaces, returning to the buccal side. It was of particular importance that both examiners had an identical level of training in scanning. Both were in the same period after their exams and were trained on all devices. If a single examiner had performed all the scans, it could be assumed that the knowledge gained in scanning over the long period from 2012 to 2021 had an influence on the results.

The analyses were based on evaluation methods already known and used in a previous study [26]; for this purpose, all scan data were first exported to a standard STL file format.

For conventional impressions $(n=10)$, the open-tray technique was used $[30,31]$. A custom tray consisting of C-Plast (Candulor Dental GmbH, Rielasingen-Worblingen, Germany; thickness $3 \mathrm{~mm}$ ) with a tubular design around the impression copings (including RCs) was fabricated. Four impression copings (N TR-RN024.8, nt-trading, Karlsruhe, Germany) were fixed into the implants $(15 \mathrm{Ncm})$. To compensate for the laboratory conditions, the impression material (Impregum Penta) was allowed to set for ten minutes ( $23 \pm 1{ }^{\circ} \mathrm{C}$ temperature, $50 \pm 10 \%$ relative humidity). Afterwards, impression post screws were loosened, and the impression was removed from the IMM. A total of ten impressions were obtained. Laboratory analogs were repositioned on the impression posts (N51, nttrading, Karlsruhe, Germany) and tightened with a torque of $15 \mathrm{Ncm}$. Using Fujirock EP (GC Corporation, Tokyo, Japan), ten plaster casts were produced and stored under laboratory conditions for seven days.

The received STL files were imported into Gom Inspect (Gom, Braunschweig, Germany) and aligned to the reference file with the RCs to measure the digital impressions. This made it possible to superimpose the respective coordinate systems within the digital impressions using the reference cuboids. To clearly determine the distances within the digital models, the distances between the reference cuboid and the implant-abutment interface points (IAIPs) were measured in the IMM. This procedure was applied to both the digital and the conventional models. Then, the absolute linear displacement $(\Delta R)$ of the IAIPs for each implant position from the digital and conventional impressions and the reference data set was calculated using $\Delta \mathrm{R}=\sqrt[2]{\left(x_{2}-x_{1}\right) 2+\left(y_{2}-y_{1}\right) 2+\left(z_{2}-z_{1}\right) 2}$. To measure the deviations of rotation and angulation, planes and cylinders were constructed at the respective scan bodies. This made it possible to compare the same planes and cylinders in 
the master model and digital models. The corresponding distances and angles are shown in Figure 2.

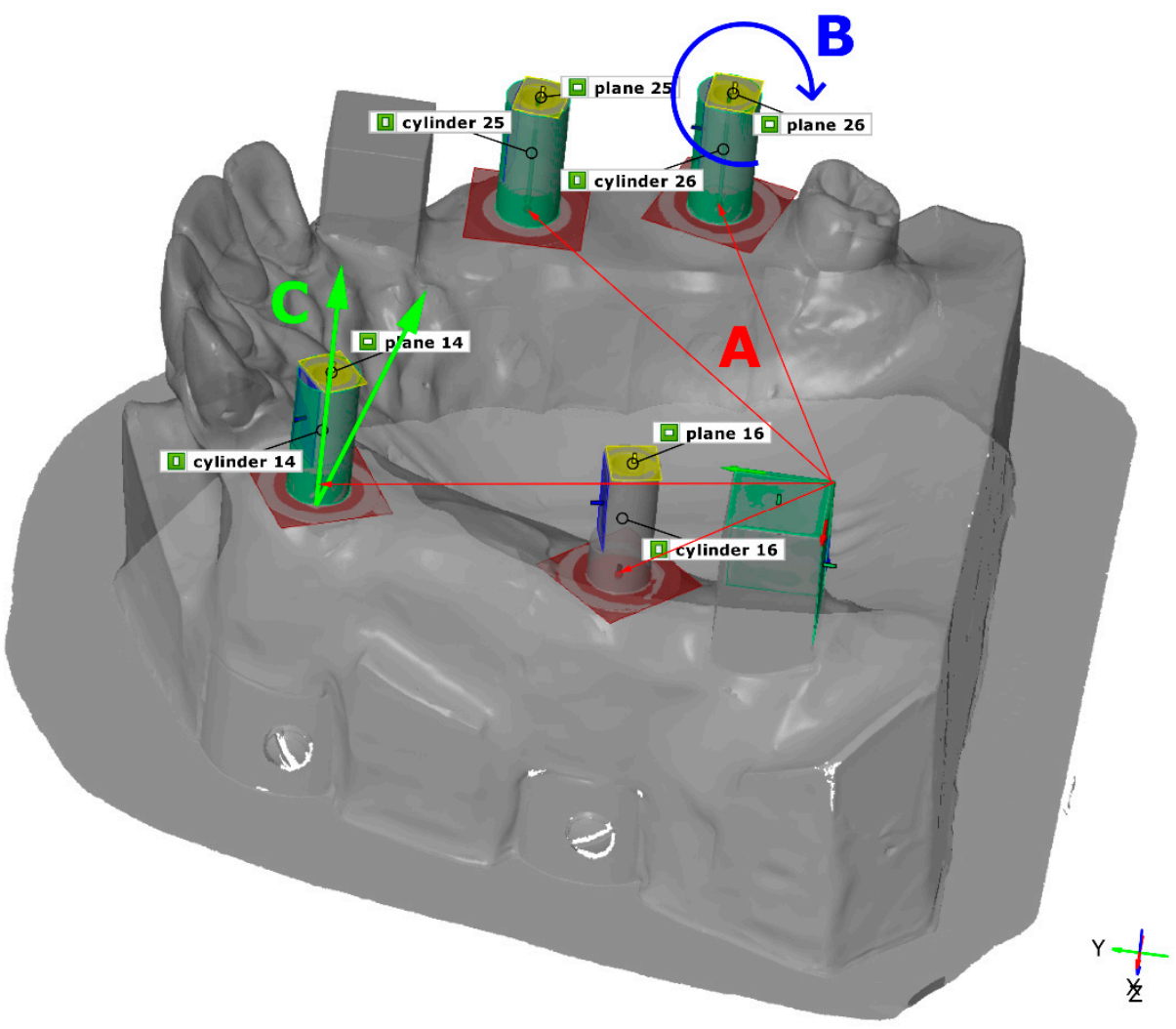

Figure 2. Schematic representation of the measured absolute three-dimensional distances (A), rotations (B), and angulations (C) within the implant master model (IMM).

To measure the IAIPs, rotation, and angulation of the gypsum models, four scan bodies (N1410, Medentika, Hügelsheim, Germany) were tightened in the implants with a torque of $15 \mathrm{Ncm}$ and measured using a CMM (RAPID, Thome, Messel, Germany) to evaluate the absolute 3D distances between the IAIPs and RC. To avoid errors that can result from even the smallest vibrations of the CMM due to manual manipulations and to increase the precision of the measurements, the following measures were taken. A program was created to standardize and automate the measurement process for all casts using the Metrolog software (Metrologic Group, Meylan, France). The program included series of predefined measurement commands (TURNING POINT, CYLINDER, PLANE) for the $\mathrm{CMM}$ with subsequent data evaluation. Within the program, the models were measured 10 times, and the arithmetic mean was calculated. This procedure was performed 10 times.

Statistical analyses were performed using SPSS version 26 (IBM, Chicago, IL, USA). The results for the deviations were analyzed using the Mann-Whitney and Kruskal-Wallis tests. As the data in some cases were not normal distributed, the results were reported using boxplot format. Though the not normal distributed results had limited relevance, they had to be considered. Mean values and standard deviations are presented in Table 2 to provide additional information and an overview over trueness and the precision according to ISO 5725-1. 
Table 2. Statistical analysis of the implant positions (FDI: 16, 14, 24, 26) and impression methods (TD_4.1: True Definition scanner (Cart version) 4.1; TD_5.4: True Definition scanner (Cart version) 5.4; TDpb_5.4: True Definition scanner (Portable version) 5.4; TR2: TRIOS II; TR 4: TRIOS 4; OC_4.2: CEREC Omnicam 4.2.1.61068; OC_4.6: CEREC Omnicam 4.6.1.152739; PS: CEREC Primescan 5.1.0.190461) for trueness and precision according to ISO 5725. Mean \pm standard deviations [ $\mu \mathrm{m}])$ of the three-dimensional deviations, deviations in rotation, and angulation. Significant differences $(p<0.05)$ are highlighted in bold type.

\begin{tabular}{|c|c|c|c|c|c|}
\hline & \multirow[t]{3}{*}{ Impression Method } & \multicolumn{4}{|c|}{$p$-Value } \\
\hline & & \multicolumn{4}{|c|}{$\begin{array}{c}\text { Trueness/Precision } \\
(\text { Mean }[\mu \mathrm{m}] \pm \text { Standard Deviation }[\mu \mathrm{m}])\end{array}$} \\
\hline & & \multicolumn{4}{|c|}{ Implant Position } \\
\hline & $\begin{array}{c}\text { Hardware/Software- } \\
\text { Version } \\
\text { (Old-New) }\end{array}$ & 16 & 14 & 25 & 26 \\
\hline \multirow{5}{*}{$\begin{array}{l}\text { Three-dimensional } \\
\text { Deviations }\end{array}$} & TD_4.1-TD_5.4 & $\begin{array}{c}<0.001 / 0.672 \\
(0.047 \pm 0.009- \\
0.101 \pm 0.013)\end{array}$ & $\begin{array}{c}<\mathbf{0 . 0 0 1 / 0 . 0 1 0} \\
(0.047 \pm 0.014- \\
0.185 \pm 0.035)\end{array}$ & $\begin{array}{c}<\mathbf{0 . 0 0 1 / 0 . 0 2 4} \\
(0.258 \pm 0.052- \\
0.515 \pm 0.103)\end{array}$ & $\begin{array}{c}\mathbf{0 . 0 1 3} / 0.135 \\
(0.355 \pm 0.062- \\
0.483 \pm 0.110)\end{array}$ \\
\hline & TD_4.1-TDpb_5.4 & $\begin{array}{c}<0.001 / 0.082 \\
(0.047 \pm 0.009- \\
0.115 \pm 0.028)\end{array}$ & $\begin{array}{c}<\mathbf{0 . 0 0 1 / 0 . 0 0 9} \\
(0.047 \pm 0.014- \\
0.192 \pm 0.069)\end{array}$ & $\begin{array}{c}<\mathbf{0 . 0 0 1 / 0 . 0 0 7} \\
(0.258 \pm 0.052- \\
0.597 \pm 0.120)\end{array}$ & $\begin{array}{c}\mathbf{0 . 0 0 2} / \mathbf{0 . 0 1 0} \\
(0.355 \pm 0.062- \\
0.632 \pm 0.184)\end{array}$ \\
\hline & TR2-TR4 & $\begin{array}{c}\mathbf{0 . 0 0 6 / 0 . 0 0 4} \\
(0.089 \pm 0.036- \\
0.044 \pm 0.011)\end{array}$ & $\begin{array}{c}<0.001 / 0.009 \\
(0.335 \pm 0.105- \\
0.092 \pm 0.043)\end{array}$ & $\begin{array}{c}\mathbf{0 . 0 0 2} / \mathbf{0 . 0 3 5} \\
(0.516 \pm 0.242- \\
0.214 \pm 0.072)\end{array}$ & $\begin{array}{c}\mathbf{0 . 0 0 1} / 0.071 \\
(0.574 \pm 0.274- \\
0.258 \pm 0.100)\end{array}$ \\
\hline & OC_4.2-OC_4.6 & $\begin{array}{c}<0.001 / 0.863 \\
(0.282 \pm 0.058- \\
0.154 \pm 0.039)\end{array}$ & $\begin{array}{c}<0.001 / 0.002 \\
(0.747 \pm 0.262- \\
0.256 \pm 0.092)\end{array}$ & $\begin{array}{c}<0.001 /<0.001 \\
(1.260 \pm 0.889- \\
0.335 \pm 0.173)\end{array}$ & $\begin{array}{c}\mathbf{0 . 0 0 1} /<0.001 \\
(1.356 \pm 1.023- \\
0.370 \pm 0.195)\end{array}$ \\
\hline & OC_4.2-PS & $\begin{array}{c}<0.001 / 0.163 \\
(0.282 \pm 0.058- \\
0.038 \pm 0.014)\end{array}$ & $\begin{array}{c}<\mathbf{0 . 0 0 1} /<\mathbf{0 . 0 0 1} \\
(0.747 \pm 0.262- \\
0.085 \pm 0.024)\end{array}$ & $\begin{array}{c}<.001 /<0.001 \\
(1.260 \pm 0.889- \\
0.115 \pm 0.053)\end{array}$ & $\begin{array}{c}<0.001 /<0.001 \\
(1.356 \pm 1.023- \\
0.110 \pm 0.049)\end{array}$ \\
\hline \multirow{5}{*}{$\begin{array}{l}\text { Rotational } \\
\text { Deviations }\end{array}$} & TD_4.1一TD_5.4 & $\begin{array}{c}<0.001 / 0.099 \\
(0.067 \pm 0.044- \\
0.312 \pm 0.078)\end{array}$ & $\begin{array}{c}<0.001 / 0.099 \\
(0.031 \pm 0.029- \\
0.237 \pm 0.108)\end{array}$ & $\begin{array}{c}\mathbf{0 . 0 0 1} / 0.605 \\
(0.108 \pm 0.073- \\
0.335 \pm 0.108)\end{array}$ & $\begin{array}{c}0.821 / 0.435 \\
(0.152 \pm 0.090- \\
0.143 \pm 0.065)\end{array}$ \\
\hline & TD_4.1-TDpb_5.4 & $\begin{array}{c}<0.001 / 0.123 \\
(0.067 \pm 0.044- \\
0.339 \pm 0.076)\end{array}$ & $\begin{array}{c}\mathbf{0 . 0 0 1 / 0 . 0 0 1} \\
(0.031 \pm 0.029- \\
0.211 \pm 0.182)\end{array}$ & $\begin{array}{c}\mathbf{0 . 0 0 4} / \mathbf{0 . 0 0 4} \\
(0.108 \pm 0.073- \\
0.640 \pm 0.354)\end{array}$ & $\begin{array}{c}\mathbf{0 . 0 0 5} / \mathbf{0 . 0 1 2} \\
(0.152 \pm 0.090- \\
0.494 \pm 0.266)\end{array}$ \\
\hline & TR2-TR4 & $\begin{array}{c}0.324 / \mathbf{0 . 0 2 6} \\
(0.161 \pm 0.125- \\
0.084 \pm 0.058)\end{array}$ & $\begin{array}{c}\mathbf{0 . 0 1 2} / \mathbf{0 . 0 0 9} \\
(0.349 \pm 0.233- \\
0.139 \pm 0.073)\end{array}$ & $\begin{array}{c}\mathbf{0 . 0 1 2} /<\mathbf{0 . 0 0 1} \\
(0.709 \pm 0.491- \\
0.206 \pm 0.131)\end{array}$ & $\begin{array}{c}\mathbf{0 . 0 0 8} / \mathbf{0 . 0 0 4} \\
(0.067 \pm 0.044- \\
0.339 \pm 0.076)\end{array}$ \\
\hline & OC_4.2-OC_4.6 & $\begin{array}{c}\mathbf{0 . 0 2 1} / 0.718 \\
(0.218 \pm 0.138- \\
0.418 \pm 0.184)\end{array}$ & $\begin{array}{c}0.405 / \mathbf{0 . 0 0 3} \\
(1.567 \pm 2.414- \\
0.404 \pm 0.247)\end{array}$ & $\begin{array}{c}\mathbf{0 . 0 0 1} / \mathbf{0 . 0 0 8} \\
(1.307 \pm 0.877- \\
0.241 \pm 0.272)\end{array}$ & $\begin{array}{c}\mathbf{0 . 0 0 6} / \mathbf{0 . 0 0 1} \\
(1.083 \pm 0.814- \\
0.313 \pm 0.221)\end{array}$ \\
\hline & OC_4.2-PS & $\begin{array}{c}0.130 / \mathbf{0 . 0 3 0} \\
(0.218 \pm 0.138- \\
0.122 \pm 0.083)\end{array}$ & $\begin{array}{c}\mathbf{0 . 0 0 8 / 0 . 0 0 2} \\
(1.567 \pm 2.414- \\
0.131 \pm 0.088)\end{array}$ & $\begin{array}{c}\mathbf{0 . 0 0 2} / \mathbf{0 . 0 0 1} \\
(1.307 \pm 0.877- \\
0.123 \pm 0.067)\end{array}$ & $\begin{array}{c}\mathbf{0 . 0 0 1} /<0.001 \\
(1.083 \pm 0.814- \\
0.123 \pm 0.070)\end{array}$ \\
\hline \multirow{5}{*}{$\begin{array}{l}\text { Angulation } \\
\text { Deviations }\end{array}$} & TD_4.1-TD_5.4 & $\begin{array}{c}0.471 / 0.724 \\
(0.052 \pm 0.047- \\
0.058 \pm 0.044)\end{array}$ & $\begin{array}{c}<0.001 / 0.681 \\
(0.251 \pm 0.119- \\
0.541 \pm 0.132)\end{array}$ & $\begin{array}{c}<0.001 / 0.525 \\
(0.194 \pm 0.082- \\
0.515 \pm 0.097)\end{array}$ & $\begin{array}{c}<0.001 / 0.638 \\
(0.101 \pm 0.092- \\
0.453 \pm 0.105)\end{array}$ \\
\hline & TD_4.1-TDpb_5.4 & $\begin{array}{c}\mathbf{0 . 0 0 6 / 0 . 4 8 7} \\
(0.052 \pm 0.047- \\
0.118 \pm 0.041)\end{array}$ & $\begin{array}{c}<0.001 / 0.401 \\
(0.251 \pm 0.119- \\
0.526 \pm 0.089)\end{array}$ & $\begin{array}{c}<0.001 / 0.072 \\
(0.194 \pm 0.082- \\
0.601 \pm 0.162)\end{array}$ & $\begin{array}{c}<0.001 / 0.210 \\
(0.101 \pm 0.092- \\
0.477 \pm 0.111)\end{array}$ \\
\hline & TR2-TR4 & $\begin{array}{c}0.290 / 0.090 \\
(0.219 \pm 0.146- \\
0.139 \pm 0.074)\end{array}$ & $\begin{array}{c}\mathbf{0 . 0 0 4} / 0.005 \\
(0.685 \pm 0.352- \\
0.299 \pm 0.100)\end{array}$ & $\begin{array}{c}<0.001 / 0.008 \\
(0.567 \pm 0.238- \\
0.130 \pm 0.069)\end{array}$ & $\begin{array}{c}\mathbf{0 . 0 1 5} / 0.007 \\
(0.374 \pm 0.224- \\
0.159 \pm 0.083)\end{array}$ \\
\hline & OC_4.2-OC_4.6 & $\begin{array}{c}0.096 / \mathbf{0 . 0 0 7} \\
(0.318 \pm 0.296- \\
0.121 \pm 0.104)\end{array}$ & $\begin{array}{c}0.705 / \mathbf{0 . 0 0 8} \\
(0.569 \pm 0.658- \\
0.236 \pm 0.087)\end{array}$ & $\begin{array}{c}0.059 / \mathbf{0 . 0 1 0} \\
(0.663 \pm 0.448- \\
0.275 \pm 0.216)\end{array}$ & $\begin{array}{c}0.054 / \mathbf{0 . 0 1 0} \\
(0.531 \pm 0.399- \\
0.183 \pm 0.139)\end{array}$ \\
\hline & OC_4.2-PS & $\begin{array}{c}0.151 / \mathbf{0 . 0 0 5} \\
(0.318 \pm 0.296- \\
0.120 \pm 0.092)\end{array}$ & $\begin{array}{c}\mathbf{0 . 0 1 9} / \mathbf{0 . 0 0 3} \\
(0.569 \pm 0.658- \\
0.055 \pm 0.039)\end{array}$ & $\begin{array}{c}\mathbf{0 . 0 2 3} /<\mathbf{0 . 0 0 1} \\
(0.663 \pm 0.448- \\
0.152 \pm 0.114)\end{array}$ & $\begin{array}{c}\mathbf{0 . 0 0 2} /<\mathbf{0 . 0 0 1} \\
(0.531 \pm 0.399- \\
0.053 \pm 0.031)\end{array}$ \\
\hline
\end{tabular}




\section{Results}

The results for the absolute 3D deviations and the rotational and angulation deviations for each implant position and the IOS are presented in Figures 3-5, according to the International Organization for Standardization (ISO) 5725 guidelines [27]. The statistical tests for all the deviations are listed in Table 2.

The results for the absolute $3 \mathrm{D}$ deviations show that the deviations increased with increasing scan path length (FDI 14-26), particularly for the digital impressions. In contrast, the conventional impression showed constant deviation over the complete arch. Furthermore, the current hardware and software versions of the IOS provide the most accurate results.

The results for the rotational deviations show that the deviations increased with increasing scan path length (FDI 14-26), particularly for the older hardware and software versions of the digital impressions. This is similar to conventional impressions. Furthermore, the current hardware and software versions of the IOS provide the most accurate results.

The results for the angulation deviations show that the deviations increased with increasing scan path length (FDI 14-26), particularly for the older hardware and software versions of the digital impressions. In contrast, the conventional impression showed constant deviation over the entire arch. Furthermore, the current hardware and software versions of the IOS provide the most accurate results.

Therefore, the null hypothesis must be rejected, as there are differences in the transfer accuracy for different IOSs with different hardware and software versions.

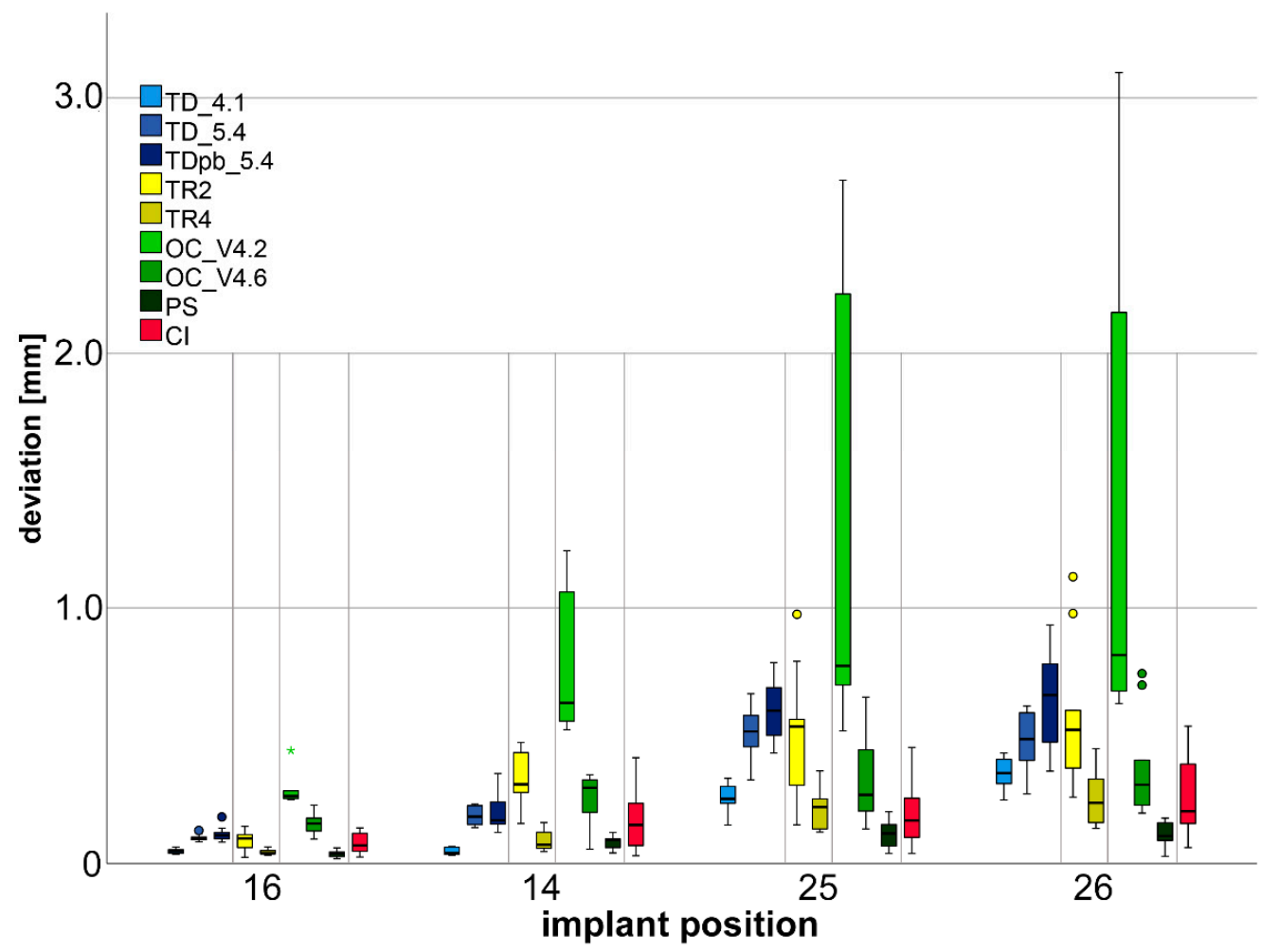

Figure 3. Results for the absolute three-dimensional deviations for the implant positions for each intraoral scanner (TD_4.1: True Definition scanner (Cart version) 4.1; TD_5.4: True Definition scanner (Cart version) 5.4; TDpb_5.4: True Definition scanner (Portable version) 5.4; TR2: TRIOS II; TR 4: TRIOS 4; OC_4.2: CEREC Omnicam 4.2.1.61068; OC_4.6: CEREC Omnicam 4.6.1.152739; and PS: CEREC Primescan 5.1.0.190461). 


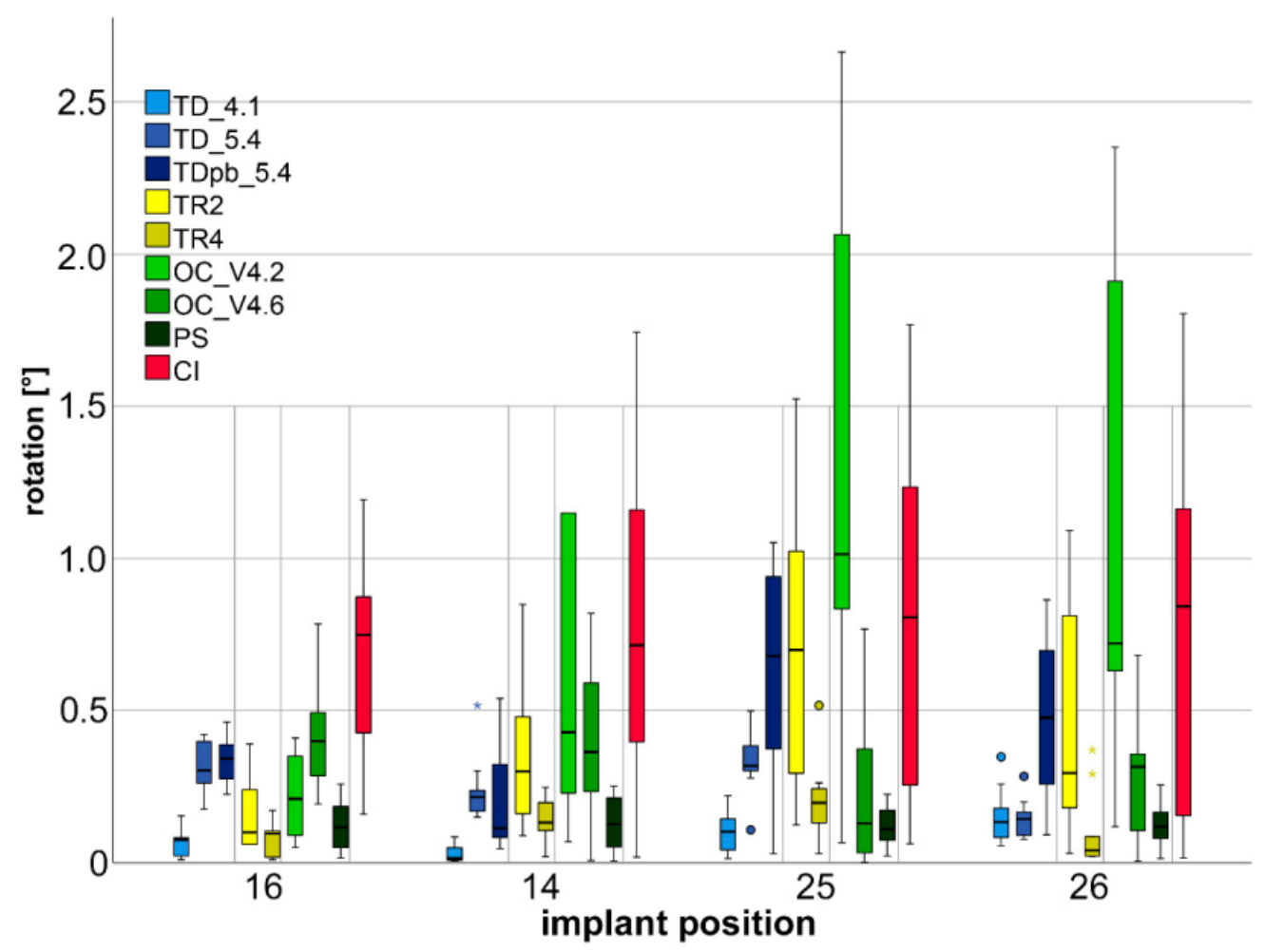

Figure 4. Results for the rotational deviations for the implant positions for each intraoral scanner (TD_4.1: True Definition scanner (Cart version) 4.1; TD_5.4: True Definition scanner (Cart version) 5.4; TDpb_5.4: True Definition scanner (Portable version) 5.4; TR2: TRIOS II; TR 4: TRIOS 4; OC_4.2: CEREC Omnicam 4.2.1.61068; OC_4.6: CEREC Omnicam 4.6.1.152739; and PS: CEREC Primescan 5.1.0.190461).

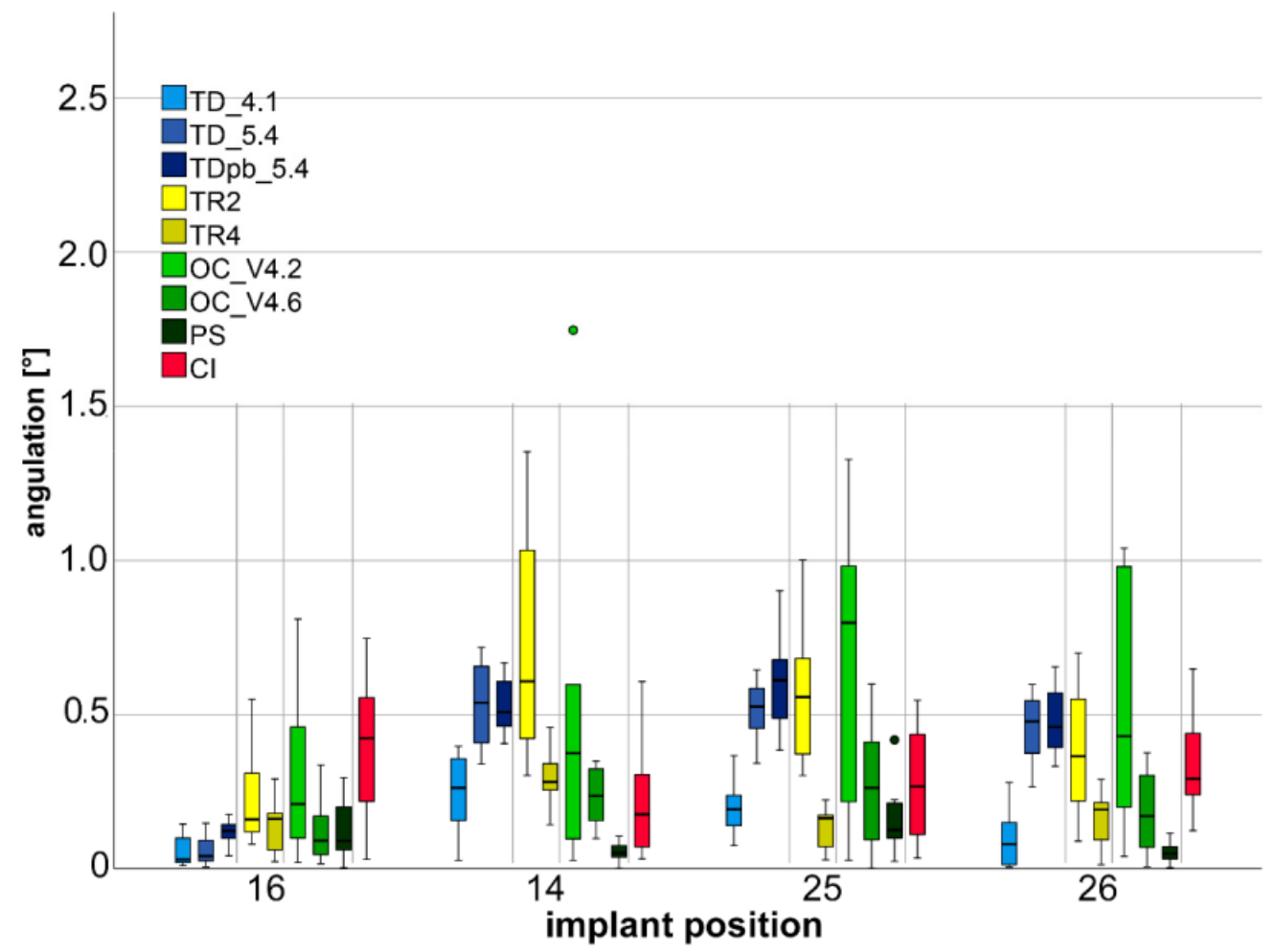

Figure 5. Results for the angulation deviations for the implant positions for each intraoral scanner (TD_4.1: True Definition scanner (Cart version) 4.1; TD_5.4: True Definition scanner (Cart version) 5.4; TDpb_5.4: True Definition scanner (Portable version) 5.4; TR2: TRIOS II; TR 4: TRIOS 4; OC_4.2: 
CEREC Omnicam 4.2.1.61068; OC_4.6: CEREC Omnicam 4.6.1.152739; and PS: CEREC Primescan 5.1.0.190461).

\section{Discussion}

The results of the present study demonstrate the influence of hardware and software development over the last decade from 2012 to 2021 on scanning accuracy. Many manufacturers offer different software updates, but at a certain point older devices are no longer supported and it is necessary to buy new hardware. Therefore, it is difficult to determine whether a decrease in transfer accuracy is solely due to the software improvement or to the hardware as well. This is a clear limitation of the current study. Moreover, newer scanner generations do not necessarily provide better results. Unlike the other IOSs examined, the current True Definition Scanner hardware and software systems showed no improvement in terms of transfer accuracy in later versions. This may be related to the computing power of the tablet computer used, particularly in the case of a portable scanner. Furthermore, it may possibly be due to the presence of the reference structures within the model, as the scanners are typically intended to capture tooth structures or scan bodies. Furthermore, it may occur by reducing the powdering, which is recommended by the manufacturer. This was particularly noticeable in preliminary tests, but an absolute statement regarding the scan algorithms is not given by the manufacturers' side, so no absolute statement regarding this possibility is feasible; this is also a clear limitation of the present study. In contrast, the combination of two acquisition principles in a single device appears to significantly increase the accuracy, as observed in the Primescan IOS [28,29]. The fact that an additional scanning principle is used in comparison to the Omnicam shows that the manufacturer is trying to further develop the scanner, which is part of the CEREC family. This may be related to inherent limitations when using only one scanning principle, which can only be overcome by combining several scanning principles.

In the present study, a common problem with four implants inserted in the maxilla was simulated. With the help of the reference system, the absolute three-dimensional (3D) deviations and rotational and angulation deviations could be assessed. For comparison, a conventional impression using impression material available over the last decade was included [22,23]. The same (intraoral) scan bodies were used to obtain comparable results, as different scan bodies can lead to different transfer accuracies. Although various techniques are available for conventional implant impressions, an open-tray technique with a polyether was used for comparison. This technique was often used in previous studies and showed the highest transfer accuracy [30-32].

Measurement errors were avoided as measurements were performed only by two investigators (H. L. and H. S. K.). To obtain the utmost accuracy, individual scanning paths recommended by the respective manufacturers were used [10]. A lot of studies on impression and scanning accuracy rely only on surface comparisons [33-35]. However, this method may hide real differences $[25,36]$. Therefore, one strength of the present study was using a reference system within the IMM, which allowed the determination of the precisely $\mathrm{x}-, \mathrm{y}-$, and $\mathrm{z}$-deviations for the different implant positions. In contrast to the best-fit method, this approach made it possible to obtain an accurate $3 \mathrm{D}$ interpretation of the results. This approach, however, requires an RC or another reference structure, which is only achievable in an in vitro setup. Though this prerequisite is a clear limitation for clinical studies, it is a strength of the present study, as we aimed to compare the different scanners in families with the utmost precision.

Concerning the accuracy of the analysis, we assessed trueness and precision according to ISO 5725-1. We chose the ISO approach as a standardized method, which is very helpful for comparing our results with those of previous studies later on [16]. Although this method is commonly used according to the ISO standard, different approaches to the evaluation of precision were reported [37,38]. 
In principle, the comparison to other studies is difficult, since only a few studies use an $\mathrm{RC}$, and these alone allow a three-dimensional evaluation. Furthermore, clinical studies tend to a lower trueness due to the presence of saliva and possible movements of the patient. When comparing the results to the literature, the respective date of publication as well as the hardware and software version used within the respective study must be taken into account. With regard to the results of TD_4.1, similar results were obtained in a study by Gimenez et al. $[39,40]$. Similar values were also obtained for the angular changes as in the present study. The results of the TR2 are comparable to a study by Medina-Sotomayor et al. [41,42], and the results of the study by Vandeweghe et al. [43]. The results of OC_4.2 were remarkably high for all measurements. These results could be confirmed by a study by Jeong et al. [44]. Within a clinical study by Kuhr et al. [14], even higher values could be determined. In contrast, investigations by Ender et al. [11,34] showed more accurate results for the Omnicam with the old software version. However, it must be noted that the upper and lower $10-20 \%$ of the measured values were not included in the results due to the evaluation. However, this reflects exactly the extreme values of the deviations to which the old software version could tend.

With regard to the digital impressions conducted with the new hardware and software versions, higher deviations could be measured within an investigation by Moura et al. [45]. However, this may be due to a different evaluation method of the linear distances. Lower deviations were found in investigations by Menini et al. [46], Papaspyridakos et al. [18], and Rutkunas et al. [47]. It is hypothesized that the small distances between the implants are decisive factors which typically cause only small deviations in the transfer accuracy.

Similar results were obtained by Amin et al. [17], Chew et al. [48], Flügge et al. [49], Rech-Ortega et al. [50], and Revilla-León et al. [51].

Nevertheless, other studies report similar results for the CI in an accuracy range of 11 to 70 micrometers such as studies by Gedrimiene et al. [52], Moura et al. [45], Rech-Ortega et al., Revilla-León et al. [50], and Rutkunas et al. [47]. The inaccuracies in the older optical triangulation technique and confocal scanners increased with the progression of the scan path. It is hypothesized that the ongoing increase in the inaccuracies from the start of scan path (implant 14) to the end of scanning path (26) was related to the summation of errors from the partial incomplete superimposition of the scanned images. These results are consistent with those of earlier studies [43,49], except for in [17], where no increase in errors with the progress of the scan path was observed for optical triangulation and active wavefront sampling systems. However, this difference may be due to a possible camouflage effect of the best-fit algorithm [25] used in the study from Amin et al. [17]. However, this challenge appears to diminish in more recent scanners, which has also been described by O'Toole et al. [53].

As anticipated, the results for the conventional impressions were not affected by the implant position, which is consistent with previous studies [14,17]. The partially higher deviations regarding the absolute 3D deviations are due to the necessary pull-off forces from the model, which were unavoidable owing to the plane-parallel reference bodies present in the model. It can be assumed that these are lower in the patient; however, there may also be undercuts in clinical situations. It was found that the conventional impressions showed higher inaccuracies, particularly in the rotation and angulation deviations. This may be due to the numerous changeover procedures required compared to digital impressions (screwing in the impression post, screwing on the laboratory analog, screwing in the scan body for measurement). Although the measurement of the conventional impression could have been performed directly, this is not possible in daily practice.

For everyday clinical work, however, it should be noted that the data from a received IOS is typically not used immediately, but is first processed into a digital model with the help of model builder software. In this way, acquisition errors can be reduced when aligning the computer-aided design data from the scan body (from the model builder's software library) to the STL data set from the scanning device. Therefore, in clinical reality, the resulting error may be smaller, as suggested by our results and those of a previous study [54]. 
In summary, our data showed that two of the scanner families investigated here have been decisively further developed within the last decade.

\section{Conclusions}

Based on the results of the present study, the following conclusions can be drawn.

The scanning accuracy of IOS is decisively related to hardware and software version; though, newer systems or software versions do not necessarily warrant improvement. Nevertheless, to achieve high transfer accuracy, regular updating of digital systems is recommended. The challenge of increasing errors with increasing scan paths is overcome in the most recent systems. The combination of two different scanning principles in a single device seems to be beneficial. Based on the data of the present study, it can be concluded that the potential of future intraoral scanner systems seems to be further improved and that digital impression techniques may replace conventional impression techniques in the near future. However, several other aspects, such as functional impression taking with intraoral scanners, need to be considered. These are still largely unresolved, so future investigations are necessary.

Author Contributions: Conceptualization, A.S. and M.A.S.; methodology, B.W.; software, A.S., H.S.K. and H.L.; validation, M.A.S., A.S. and B.W.; formal analysis, M.A.S.; investigation, H.S.K. and H.L.; resources, B.W.; data curation, A.S.; writing—original draft preparation, A.S. and M.A.S.; writing - review and editing, B.W.; visualization, M.A.S.; supervision, B.W.; project administration, A.S. All authors have read and agreed to the published version of the manuscript.

Funding: This research received no external funding.

Institutional Review Board Statement: Not applicable.

Informed Consent Statement: Not applicable.

Data Availability Statement: The datasets of this article are available from the corresponding author on a reasonable request.

Acknowledgments: We gratefully acknowledge the support of our biostatistician, Johannes Herrmann, for the statistical analysis.

Conflicts of Interest: The authors declare no conflict of interest related to this study.

$\begin{array}{ll}\text { Abbreviations } \\ \text { CMM } & \text { Coordinate measurement machine } \\ \text { IAIPs } & \text { Implant abutment interface points } \\ \text { IsB } & \text { Intraoral scan body } \\ \text { ISC } & \text { Intraoral scan } \\ \text { IMM } & \text { Implant master model } \\ \text { IOS } & \text { Intraoral scanner } \\ \text { RC } & \text { reference cube }\end{array}$

\section{References}

1. Blatz, M.B.; Conejo, J. The Current State of Chairside Digital Dentistry and Materials. Dent. Clin. N. Am. 2019, 63, 175-197. [CrossRef]

2. Michelinakis, G.; Apostolakis, D.; Kamposiora, P.; Papavasiliou, G.; Ozcan, M. The direct digital workflow in fixed implant prosthodontics: A narrative review. BMC Oral Health 2021, 21, 37. [CrossRef]

3. Schmidt, A.; Klussmann, L.; Wostmann, B.; Schlenz, M.A. Accuracy of Digital and Conventional Full-Arch Impressions in Patients: An Update. J. Clin. Med. 2020, 9, 688. [CrossRef]

4. Schmidt, A.; Rein, P.E.; Wostmann, B.; Schlenz, M.A. A comparative clinical study on the transfer accuracy of conventional and digital implant impressions using a new reference key-based method. Clin. Oral Implant. Res. 2021, 32, 460-469. [CrossRef]

5. Yatmaz, B.B.; Raith, S.; Reich, S. Trueness evaluation of digital impression: The impact of the selection of reference and test object. J. Dent. 2021, 103706. [CrossRef] [PubMed]

6. Christopoulou, I.; Kappaaklamanos, E.G.; Makrygiannakis, M.A.; Bitsanis, I.; Tsolakis, A.I. Patient-reported experiences and preferences with intraoral scanners: A systematic review. Eur. J. Orthod. 2021. [CrossRef] 
7. Zhang, Y.J.; Shi, J.Y.; Qian, S.J.; Qiao, S.C.; Lai, H.C. Accuracy of full-arch digital implant impressions taken using intraoral scanners and related variables: A systematic review. Int. J. Oral Implantol. 2021, 14, 157-179.

8. Logozzo, S.; Zanetti, E.M.; Franceschini, G.; Kilpelä, A. Recent advances in dental optics—Part I: 3D intraoral scanners for restorative dentistry. Opt. Laser. Eng. 2014, 54, 203-221. [CrossRef]

9. Rehmann, P.; Sichwardt, V.; Wostmann, B. Intraoral Scanning Systems: Need for Maintenance. Int. J. Prosthodont. 2017, 30, 27-29. [CrossRef] [PubMed]

10. Müller, P.; Ender, A.; Joda, T.; Katsoulis, J. Impact of digital intraoral scan strategies on the impression accuracy using the TRIOS Pod scanner. Quintessence Int. 2016, 47, 343-349. [CrossRef]

11. Ender, A.; Mehl, A. Influence of scanning strategies on the accuracy of digital intraoral scanning systems. Int. J. Comput. Dent. 2013, 16, 11-21.

12. Rutkunas, V.; Geciauskaite, A.; Jegelevicius, D.; Vaitiekunas, M. Accuracy of digital implant impressions with intraoral scanners. A systematic review. Eur. J. Oral Implantol. 2017, 10 (Suppl. 1), 101-120. [PubMed]

13. Boeddinghaus, M.; Breloer, E.S.; Rehmann, P.; Wostmann, B. Accuracy of single-tooth restorations based on intraoral digital and conventional impressions in patients. Clin. Oral Investig. 2015, 19, 2027-2034. [CrossRef] [PubMed]

14. Kuhr, F.; Schmidt, A.; Rehmann, P.; Wöstmann, B. A new method for assessing the accuracy of full arch impressions in patients. J. Dent. 2016, 55, 68-74. [CrossRef]

15. Giachetti, L.; Sarti, C.; Cinelli, F.; Russo, D.S. Accuracy of Digital Impressions in Fixed Prosthodontics: A Systematic Review of Clinical Studies. Int. J. Prosthodont. 2020, 33, 192-201. [CrossRef]

16. Keul, C.; Güth, J.F. Accuracy of full-arch digital impressions: An in vitro and in vivo comparison. Clin. Oral Investig. 2020, 24, 735-745. [CrossRef]

17. Amin, S.; Weber, H.P.; Finkelman, M.; El Rafie, K.; Kudara, Y.; Papaspyridakos, P. Digital vs. conventional full-arch implant impressions: A comparative study. Clin. Oral Implants Res. 2017, 28, 1360-1367. [CrossRef]

18. Papaspyridakos, P.; Vazouras, K.; Chen, Y.W.; Kotina, E.; Natto, Z.; Kang, K.; Chochlidakis, K. Digital vs. Conventional Implant Impressions: A Systematic Review and Meta-Analysis. J. Prosthodont. 2020, 29, 660-678. [CrossRef] [PubMed]

19. Haddadi, Y.; Bahrami, G.; Isidor, F. Effect of Software Version on the Accuracy of an Intraoral Scanning Device. Int. J. Prosthodont. 2018, 31, 375-376. [CrossRef]

20. Shim, J.S.; Lee, J.S.; Lee, J.Y.; Choi, Y.J.; Shin, S.W.; Ryu, J.J. Effect of software version and parameter settings on the marginal and internal adaptation of crowns fabricated with the CAD/CAM system. J. Appl. Oral Sci. 2015, 23, 515-522. [CrossRef] [PubMed]

21. Vag, J.; Renne, W.; Revell, G.; Ludlow, M.; Mennito, A.; Teich, S.T.; Gutmacher, Z. The effect of software updates on the trueness and precision of intraoral scanners. Quintessence Int. 2021, 52, 2-10. [CrossRef]

22. Chang, P.K.; Chen, Y.C.; Huang, C.C.; Lu, W.H.; Chen, Y.C.; Tsai, H.H. Distribution of micromotion in implants and alveolar bone with different thread profiles in immediate loading: A finite element study. Int J. Oral Maxillofac. Implants 2012, 27, e96-e101. [PubMed]

23. Winter, W.; Klein, D.; Karl, M. Micromotion of Dental Implants: Basic Mechanical Considerations. J. Med. Eng. 2013, 2013, 265412. [CrossRef]

24. Schmidt, A.; Billig, J.W.; Schlenz, M.A.; Rehmann, P.; Wöstmann, B. Influence of the Accuracy of Intraoral Scanbodies on Implant Position: Differences in Manufacturing Tolerances. Int. J. Prosthodont. 2019, 32, 430-432. [CrossRef] [PubMed]

25. Schmidt, A.; Billig, J.W.; Schlenz, M.A.; Wöstmann, B. Do different methods of digital data analysis lead to different results? Int. J. Comput. Dent. 2021, 24, 157-164.

26. Schmidt, A.; Billig, J.W.; Schlenz, M.A.; Wöstmann, B. The Influence of Using Different Types of Scan Bodies on the Transfer Accuracy of Implant Position: An In Vitro Study. Int. J. Prosthodont. 2021, 34, 254-260. [CrossRef] [PubMed]

27. International Organization for Standardization. Accuracy (Trueness and Precision) of Measurement Methods and Results-Part 1: General Principles and Definitions. ISO 5725-1:1994. 1994. Available online: https:/ /www.iso.org/obp/ui/\#iso:std:iso:5725:-1: ed-1:v1:en (accessed on 10 June 2021).

28. Schlenz, M.A.; Schubert, V.; Schmidt, A.; Wostmann, B.; Ruf, S.; Klaus, K. Digital versus Conventional Impression Taking Focusing on Interdental Areas: A Clinical Trial. Int. J. Environ. Res. Public Health 2020, 17, 4725. [CrossRef] [PubMed]

29. Tewes, M.; Berner, M. Device, Method and System for Generating Dynamic Projection Patterns in a Confocal Camera. U.S. Patent US 16/003628, 12 December 2019.

30. Flügge, T.; van der Meer, W.J.; Gonzalez, B.G.; Vach, K.; Wismeijer, D.; Wang, P. The accuracy of different dental impression techniques for implant-supported dental prostheses: A systematic review and meta-analysis. Clin. Oral Implants Res. 2018, 29 (Suppl. 16), 374-392. [CrossRef]

31. Moreira, A.H.; Rodrigues, N.F.; Pinho, A.C.; Fonseca, J.C.; Vilaca, J.L. Accuracy Comparison of Implant Impression Techniques: A Systematic Review. Clin. Implant Dent. Relat. Res. 2015, 17 (Suppl. 2), e751-e764. [CrossRef]

32. Stimmelmayr, M.; Erdelt, K.; Güth, J.F.; Happe, A.; Beuer, F. Evaluation of impression accuracy for a four-implant mandibular model-a digital approach. Clin. Oral Investig. 2012, 16, 1137-1142. [CrossRef]

33. Ender, A.; Attin, T.; Mehl, A. In vivo precision of conventional and digital methods of obtaining complete-arch dental impressions. J. Prosthet. Dent. 2016, 115, 313-320. [CrossRef]

34. Ender, A.; Mehl, A. Full arch scans: Conventional versus digital impressions-An in-vitro study. Int. J. Comput. Dent. 2011, $14,11-21$. 
35. Gan, N.; Xiong, Y.; Jiao, T. Accuracy of Intraoral Digital Impressions for Whole Upper Jaws, Including Full Dentitions and Palatal Soft Tissues. PLoS ONE 2016, 11, e0158800. [CrossRef]

36. Ameza-Lasuen, X.; Iturrate-Mendieta, M.; Oriozabala-Brit, J.A.; Garikano-Osinaga, X.; Martin-Amundarain, I.; Solaberrieta-Mendez, E. Best-Fit Alignment in the Digital Dental Workflow. In Advances in Design Engineering: Proceedings of the XXIX International Congress INGEGRAF; Cavas-Martínez, F., Sanz-Adan, F., Morer Camo, P., Lostado Lorza, R., Santamaría Peña, J., Eds.; Springer: Berlin/Heidelberg, Germany, 2020; pp. 202-211.

37. Ender, A.; Mehl, A. Accuracy of complete-arch dental impressions: A new method of measuring trueness and precision. J. Prosthet. Dent. 2013, 109, 121-128. [CrossRef]

38. Aswani, K.; Wankhade, S.; Khalikar, A.; Deogade, S. Accuracy of an intraoral digital impression: A review. J. Indian Prosthodont. Soc. 2020, 20, 27-37. [CrossRef] [PubMed]

39. Gimenez, B.; Ozcan, M.; Martinez-Rus, F.; Pradies, G. Accuracy of a digital impression system based on active wavefront sampling technology for implants considering operator experience, implant angulation, and depth. Clin. Implant Dent. Relat. Res. 2015, 17 (Suppl. 1), e54-e64. [CrossRef] [PubMed]

40. Gimenez-Gonzalez, B.; Hassan, B.; Ozcan, M.; Pradies, G. An In Vitro Study of Factors Influencing the Performance of Digital Intraoral Impressions Operating on Active Wavefront Sampling Technology with Multiple Implants in the Edentulous Maxilla. J. Prosthodont. 2017, 26, 650-655. [CrossRef] [PubMed]

41. Medina-Sotomayor, P.; Pascual-Moscardo, A.; Camps, I. Accuracy of four digital scanners according to scanning strategy in complete-arch impressions. PLoS ONE 2018, 13, e0202916. [CrossRef]

42. Medina-Sotomayor, P.; Pascual-Moscardo, A.; Camps, I. Relationship between resolution and accuracy of four intraoral scanners in complete-arch impressions. J. Clin. Exp. Dent. 2018, 10, e361-e366. [CrossRef]

43. Vandeweghe, S.; Vervack, V.; Dierens, M.; De Bruyn, H. Accuracy of digital impressions of multiple dental implants: An in vitro study. Clin. Oral Implants Res. 2017, 28, 648-653. [CrossRef]

44. Jeong, I.D.; Lee, J.J.; Jeon, J.H.; Kim, J.H.; Kim, H.Y.; Kim, W.C. Accuracy of complete-arch model using an intraoral video scanner: An in vitro study. J. Prosthet Dent. 2016, 115, 755-759. [CrossRef]

45. Moura, R.V.; Kojima, A.N.; Saraceni, C.H.C.; Bassolli, L.; Balducci, I.; Ozcan, M.; Mesquita, A.M.M. Evaluation of the Accuracy of Conventional and Digital Impression Techniques for Implant Restorations. J. Prosthodont. 2019, 28, e530-e535. [CrossRef]

46. Menini, M.; Setti, P.; Pera, F.; Pera, P.; Pesce, P. Accuracy of multi-unit implant impression: Traditional techniques versus a digital procedure. Clin. Oral Investig. 2018, 22, 1253-1262. [CrossRef]

47. Rutkunas, V.; Gedrimiene, A.; Adaskevicius, R.; Al-Haj Husain, N.; Ozcan, M. Comparison of the Clinical Accuracy of Digital and Conventional Dental Implant Impressions. Eur. J. Prosthodont. Restor. Dent. 2020, 28, 173-181. [CrossRef]

48. Chew, A.A.; Esguerra, R.J.; Teoh, K.H.; Wong, K.M.; Ng, S.D.; Tan, K.B. Three-Dimensional Accuracy of Digital Implant Impressions: Effects of Different Scanners and Implant Level. Int. J. Oral Maxillofac. Implants 2017, 32, 70-80. [CrossRef] [PubMed]

49. Flügge, T.V.; Att, W.; Metzger, M.C.; Nelson, K. Precision of Dental Implant Digitization Using Intraoral Scanners. Int. J. Prosthodont. 2016, 29, 277-283. [CrossRef] [PubMed]

50. Rech-Ortega, C.; Fernandez-Estevan, L.; Sola-Ruiz, M.F.; Agustin-Panadero, R.; Labaig-Rueda, C. Comparative in vitro study of the accuracy of impression techniques for dental implants: Direct technique with an elastomeric impression material versus intraoral scanner. Med. Oral Patol. Oral Cir. Bucal 2019, 24, e89-e95. [CrossRef] [PubMed]

51. Revilla-Leon, M.; Att, W.; Ozcan, M.; Rubenstein, J. Comparison of conventional, photogrammetry, and intraoral scanning accuracy of complete-arch implant impression procedures evaluated with a coordinate measuring machine. J. Prosthet. Dent. 2021, 125, 470-478. [CrossRef]

52. Gedrimiene, A.; Adaskevicius, R.; Rutkunas, V. Accuracy of digital and conventional dental implant impressions for fixed partial dentures: A comparative clinical study. J. Adv. Prosthodont. 2019, 11, 271-279. [CrossRef] [PubMed]

53. O'Toole, S.; Osnes, C.; Bartlett, D.; Keeling, A. Investigation into the accuracy and measurement methods of sequential 3D dental scan alignment. Dent. Mater. 2019, 35, 495-500. [CrossRef]

54. Mizumoto, R.M.; Yilmaz, B.; McGlumphy, E.A., Jr.; Seidt, J.; Johnston, W.M. Accuracy of different digital scanning techniques and scan bodies for complete-arch implant-supported prostheses. J. Prosthet. Dent. 2020, 123, 96-104. [CrossRef] [PubMed] 